\title{
Interação mãe-bebê com deficiência visual: estilos comunicativos e episódios interativos
}

\section{Interaction between mothers and infants with visual impairment: communicative styles and interactive episodes}

\author{
Carolina Silva de MEDEIROS \\ Nádia Maria Ribeiro SALOMÃO
}

\begin{abstract}
Resumo
Este estudo objetivou analisar a interação mãe-bebê com deficiência visual, por meio dos estilos de fala materna, dos comportamentos não verbais maternos e infantis e dos episódios interativos. Participaram da pesquisa três díades, sendo os bebês deficientes visuais, na faixa etária dos seis aos trezes meses de vida. Foi utilizada uma câmera de vídeo para apreender as interações entre as díades, em uma situação de brinquedo livre. Para cada díade foram realizadas três filmagens, cada uma com duração de vinte minutos. Os resultados sugerem que as interações entre as mães e os bebês deficientes visuais acontecem, principalmente, através da coordenação da fala com a ação gestual, na qual o toque e os movimentos corporais são utilizados com a função de facilitar a comunicação. Estudos que investigam a interação mãe-bebê com desenvolvimento atípico são relevantes, pois respondem a questões teóricas sobre o desenvolvimento e possibilitam estruturar intervenções.
\end{abstract}

Unitermos: Comunicação. Pessoas com deficiência visual. Relações mãe-criança.

\begin{abstract}
The aim of this study was to investigate the mother-infant with visual impairment interaction, by means of maternal speech styles, nonverbal behaviors and interactive episodes of mother and child. Three dyads participated in the study, and the visually impaired babies were aged from six to thirteen months. A video camera was used to capture the interactions between dyads in a free-play situation. For each dyad, three filming sessions were held, each lasting twenty minutes. The results suggested that interactions between mothers and visually impaired babies mainly takes place through the coordination of speech with the gestural action, in which touch and body language are used in order to facilitate communication. Studies that investigate the interaction of mothers of children with atypical development are relevant, because they answer theoretical questions about development and make it possible to structure interventional strategies.
\end{abstract}

Uniterms: Communication. Visualy impairment persons. Mother child relations.

A Perspectiva da Interação Social dos Estudiosos

da Linguagem assinala a importância do input materno na aquisição linguística infantil. A ideia básica da interação social é de que a linguagem, para se

\footnotetext{
$\operatorname{crv}$

1 Universidade Federal da Paraíba, Programa de Pós-Graduação em Psicologia Social, Departamento de Psicologia. Cidade Universitária, 58059-900, João Pessoa, PB, Brasil. Correspondência para/Correspondence to: C.S. MEDEIROS. E-mail: <carolinasdm@gmail.com>.

Artigo elaborado a partir da dissertação de C.S. MEDEIROS, intitulada "Estilos comunicativos e interação mãe-bebê com deficiência visual". Universidade Federal da Paraíba; 2010. Apoio: Coordenação de Aperfeiçoamento de Pessoal de Nível Superior.
} 
desenvolver, necessita de constantes trocas interativas entre o indivíduo e as pessoas presentes em seu meio social.

As primeiras pessoas com as quais a criança estabelece relação são fundamentais para o desenvolvimento de suas habilidades linguísticas, cognitivas e de conhecimento. Para Seidl de Moura et al. (2008), as interações sociais são, de certo modo, organizadas pelo contexto cultural, sendo através dele e das atividades socialmente estabelecidas que a comunicação irá se firmar. Nesse sentido, a aquisição linguística acontece dentro de um contexto social em que os pais ajustam a fala quando se dirigem aos filhos, de modo a favorecer a participação deles na relação e, posteriormente, a compreensão no uso convencional das palavras (Pérez-Pereira, 2004).

Para Snow (1997), a fala dirigida às crianças (input) é caracterizada como uma fala simples, fluente, porém com um vocabulário limitado, já que se destina a quem ainda não adquiriu a linguagem verbal propriamente dita. A fala dirigida à criança por vezes se limita ao aqui-agora, relacionando-se com o foco da atenção da criança ou com a atividade que está sendo realizada. Introduz referentes que não estão presentes e se caracteriza, além dos fatores já citados, pela presença de um tom agudo e um padrão de entonação exagerado (Bates, Dale \& Thal, 1997).

São vários os tipos de inputs, sendo o motherese (ou manhês) um dos mais encontrados nas pesquisas e nos estudos da Perspectiva da Interação Social. Esse tipo de input tem a função de envolver a criança na interação, a partir do reconhecimento de sinais apresentados durante a comunicação (Vila, 1995). Estudiosos da perspectiva da Interação Social (Conti-Ramsden, 1990; 1994; Pine, 1994; Snow, 1997) afirmam que a fala motherese ajusta-se às características do bebê pré-linguístico, visto que, além de ter uma entonação própria e simplificada, versa sobre aspectos que the são familiares e frequentemente faz referências aos significados atribuídos a suas ações.

Para Borges \& Salomão (2003), é preciso entender a fala motherese de acordo com os interesses e as disposições da criança, uma vez que essa fala utiliza formas específicas e diferenciadas da linguagem. Esses ajustes realizados podem tanto favorecer como dificultar a aqui-

752 sição da linguagem. De acordo com Braz e Salomão
(2002), os ajustes ou as adaptações consistem em uma adequação da fala em ritmo, extensão e entonação a um nível simplificado, se comparado à fala adulta, que é dirigida ao bebê e que atua de modo a envolvê-lo na interação. No motherese também é ressaltado o aspecto conversacional, isto é, o seu uso é designado para promover a participação infantil.

No motherese podem ser observados alguns estilos linguísticos que facilitam e/ou dificultam a comunicação adulto-criança e consequentemente a aquisição da linguagem infantil. Os feedbacks de reformulação e/ou expansão, por exemplo, caracterizam-se pela mudança na fala da criança, no sentido de esclarecer o conteúdo, favorecendo e estimulando sua atenção (Nelson, Welsch, Camarata, Butkovsky \& Camarata,1995).

Outro estilo linguístico comumente presente nas primeiras interações são os diretivos. Apesar das controvérsias quanto a sua real função, os diretivos caracterizam-se por comandos, ordens e instruções dadas às crianças. Segundo Hampson e Nelson (1993), são vários os modos pelos quais os enunciados diretivos surgem, variando de acordo com as características individuais da criança, com seu nível de desenvolvimento cognitivo e linguístico e com a faixa etária. Snow (1997) afirma que esse estilo de input é característico de mães de crianças com desenvolvimento atípico. De fato, em crianças com desenvolvimento atípico, os diretivos, do tipo solicitação de atenção, por exemplo, são utilizados com a função de atrair a atenção da criança para a situação e podem ser vistos como favorecedores para a aquisição da linguagem, além de serem um tipo de input bastante frequente na interação mãe-bebê nos primeiros anos de vida (Fônseca \& Salomão, 2005).

Os enunciados linguísticos podem expressar variadas intenções comunicativas e apresentar diferentes funções diante das trocas interativas. Nesse sentido, através da identificação de episódios interativos, com destaque para os contextos de atenção conjunta, é possível apreender as funções comunicativas dos enunciados apresentados.

Considera-se, portanto, que os contextos de atenção conjunta são também essenciais para a aquisição da linguagem, pois atuam como diferenciais na aprendizagem de novos vocábulos e possibilitam a construção de significados por parte da criança e daquilo que está sendo apresentado pelo adulto (Aquino \& 
Salomão, 2009; Tomasello, 2003). Caracterizam-se por comportamentos não verbais, presentes em uma relação em que, além do adulto e do bebê, há o compartilhamento da atenção para com um terceiro evento ou objeto. Com frequência, os estudiosos consideram que essa é uma habilidade importante, por sua relação com outros aspectos do desenvolvimento, como os aspectos simbólicos, linguísticos, cognitivos e/ou sociais (Oliveira \& Gil, 2007; Rochat, 2007).

Akthar, F. Dunham e P. Dunham (1991) afirmam que as mães podem utilizar os comportamentos não verbais dos bebês (sorriso, choro etc.) para que a atenção conjunta seja mantida. Esses comportamentos se mostram essenciais para a comunicação pré-verbal dos bebês, evidenciando mais uma vez a importância da relação entre díades.

Embora na maioria dos estudos empíricos a atenção conjunta esteja sendo definida como atenção visual compartilhada, ela vai além da orientação visual, o que a leva a ir além da visão simultânea. É necessário ressaltar que o simples fato de um adulto e uma criança estarem olhando para o mesmo estímulo não tem sido considerado como evidência da atenção conjunta. A criança precisa alternar sua contemplação entre o terceiro objeto e o adulto, a fim de mostrar que não apenas está focada no mesmo objeto que ele, mas também está coordenando esse foco através do engajamento de ambos (Tomasello, 2003). Segundo Akthar e Gernsbacher (2007), a atenção conjunta, conforme é definida na maioria das pesquisas, falha nas modalidades não visuais da atenção, visto que desconsidera as variações culturais e os diferentes estilos de interação entre pais e crianças.

Em bebês com desenvolvimento atípico, como é o caso daqueles com deficiência visual, a atenção conjunta pode se estabelecer por meio de outras funções perceptíveis, como a função tátil e a auditiva (Bosa \& Souza, 2007; Kreutz \& Bosa, 2009). Será nos contextos de atenção conjunta que as diversas intenções comunicativas e ações verbais se aperfeiçoarão, dando oportunidade à criança de estabelecer gradativamente um paralelismo entre os objetos, ações e seus referentes linguísticos (Braz \& Salomão, 2002).

Fraiberg (1979) ao descrever estudos com bebês deficientes visuais assinala o quão desconcertanteé para as mães a ausência da visão, visto que, muitas vezes, a discriminação, o reconhecimento, a preferência e a validade são sinais que elas normalmente obtêm através das respostas visuais das crianças. A ausência de retorno através da troca de olhar dá ideia de falta de interesse. Segundo Fraiberg (1979), mesmo quando o bebê deficiente visual revela suas vontades ou intenções através da expressão motora das mãos, não somente é necessária uma leitura cuidadosa, mas há várias intenções que não podem ser expressas através das mãos sem orientação e gestos que as identifiquem. O diálogo vocal que está presente para o bebê cego e seus pais é o único canal que permanece aberto e disponível como um sistema relativamente não distorcido entre ambos.

Um estudo realizado por Peréz-Pereira e Conti-Ramsden (2001) teve com objetivo descrever o desempenho pragmático da linguagem, tendo como foco de análise a interação entre crianças com deficiência visual, ou com desenvolvimento normal, e suas mães. Participaram seis crianças, sendo duas cegas, duas com baixa visão e duas com visão normal, além das respectivas mães. Foram feitas duas filmagens de interação mãe-criança, uma sessão livre e uma planejada, cada uma com duração de 20 minutos. Os dados obtidos foram categorizados e os resultados indicaram alta frequência do uso de comportamentos não verbais por parte das crianças.

Pérez-Pereira e Conti-Ramsden (2001) afirmam que as mães de crianças com deficiência visual parecem descrever mais o ambiente. Nas crianças com deficiência visual, as descrições feitas pelas mães tornam-se, pois, extremamente relevantes. Batista (1997) assinala que, na literatura, o vocabulário das crianças com deficiência visual está fundado em experiências perceptivas, não sendo apenas uma imitação do vocabulário dos videntes. Essas experiências ampliam a importância dos pais em assegurar não apenas uma experiência perceptual viva, mas também que ela seja inserida em um contexto de comunicação compartilhada.

Um estudo longitudinal desenvolvido por Bigelow (2003) com duas crianças cegas teve como objetivo documentar o início da atenção conjunta através da observação de seus comportamentos. A autora propôs testar a afirmação de que a atenção conjunta emerge em crianças cegas após o estágio quatro do período sensório-motor, e testar a habilidade das crianças em procurar objetos, o que indicaria a aquisição do conheci- 
mento de si. Nesse sentido, o estudo foi realizado com dois meninos, nos períodos de 13 a 21 meses e de 23 a 30 meses de vida, congenitamente cegos. A seleção dos comportamentos relacionados com a atenção conjunta foi determinada pela observação dos comportamentos das crianças e fez-se também uma categorização das ações que incorporaram as habilidades não visuais, indicando atenção conjunta.

Os resultados sugeriram que as crianças demonstraram indícios da atenção conjunta. Embora as crianças cegas sejam dependentes dos outros para apresentar suas competências físicas e sociais, essa dependência não indica que existe passividade no envolvimento com a atenção conjunta. As crianças cegas têm mais dificuldade em explorar o ambiente, em compreenderem as suas posições para com o ambiente físico e os objetos nele presentes. Logo, a dificuldade que as crianças deficientes visuais enfrentam põe em evidência a importância da visão no estabelecimento da atenção conjunta. Todavia, a ausência da visão não impede que a atenção conjunta se estabeleça, podendo acontecer por meio dos estímulos táteis e auditivos. Bigelow (2003) assinala que a aquisição da linguagem em crianças deficientes visuais leva-as a detectar a atenção dos outros, e a produção da linguagem por parte delas é, provavelmente, a ferramenta mais poderosa na direção de outros para o foco de atenção dos objetos.

Com base no exposto, este estudo teve como objetivo principal analisar a interação mãe-bebê com deficiência visual, em um contexto de brincadeira livre, mediante a identificação dos comportamentos comunicativos maternos e infantis bem como a descrição de episódios interativos.

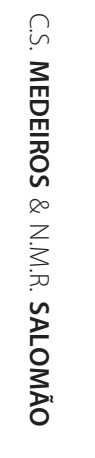

\section{Participantes}

Participaram deste estudo três díades mãe-bebê, sendo os três bebês deficientes visuais totais (cegos), isto é, não utilizam a visão como apreensão das informações sensoriais, fazendo uso de outras funções, como tato e audição. O critério de inclusão para os bebês foi de que estivessem na faixa etária dos seis aos treze meses, no início das observações e que apresentassem defi-

754 ciência visual total. Para as mães, o critério de inclusão utilizado foi de que tivessem idade acima dos dezoito anos e permanecessem com o bebê participante por pelo menos um turno do dia. A idade das mães variou dos 22 aos 35 anos. Em relação aos bebês, os três bebês com deficiência visual eram do gênero feminino, todos resultantes da retinopatia da prematuridade, ou seja, nasceram de parto prematuro e devido ao excesso de oxigênio presente na incubadora, obtiveram um deslocamento na retina, causando uma deficiência visual total. Também conhecida como amaurose, a cegueira total corresponde à completa perda da visão e, nesse sentido, o reconhecimento de objetos dá-se por meio de ações motoras (Oliveira \& Marques, 2005).

\section{Instrumentos}

Para conhecer os comportamentos comunicativos das díades foi utilizada uma câmera de vídeo digital e um cronômetro. O cronômetro serviu para demarcar o tempo de 20 minutos para cada observação realizada. Os dados obtidos através das sessões de observação constituíram o recurso metodológico principal para a análise dos comportamentos comunicativos verbais e não verbais.

\section{Procedimentos}

Destaca-se que a presente pesquisa considera a Resolução MS 196/96 do Conselho Nacional de Saúde, segundo a qual as pesquisas que envolvem seres humanos precisam ser submetidas a aprovação de um comitê de ética. Logo, este estudo foi aprovado pelo Comitê de Ética em Pesquisa do Centro de Ciências da Saúde da Universidade Federal da Paraíba - CEP/CCS, Protocolo no 0326, em 30/07/2008, e todas as mães participantes assinaram um Termo de Consentimento Livre e Esclarecido (TCLE) antes de sua inclusão na amostra. Para o consentimento da participação dos bebês, foi entregue também um TCLE aos responsáveis legais, isto é, não apenas as mães, mas também os pais assinaram o Termo.

Houve muitas dificuldades em encontrar bebês com deficiência visual total com até treze meses de vida. Através de visitas a instituições de referência, foram obtidos relatos dos profissionais, os quais afirmaram a 
diminuição da deficiência visual congênita e a dificuldade em fechar um diagnóstico de uma possível deficiência visual total no primeiro ano de vida do bebê, visto que os pais muitas vezes demoram a procurar ajuda especializada por acreditarem que a deficiência é temporária e, consequentemente, reversível. Os discursos dos profissionais corroboram a afirmação de Kreutz e Bosa (2009) de que a população de deficientes visuais é bastante diferenciada e suas causas são múltiplas.

Destarte, o contato inicial com as díades participantes aconteceu por meio de visita a algumas instituições de referência no atendimento de crianças deficientes visuais, mas as observações ocorreram nas residências das díades, dando preferência por um momento do dia em que estivessem presente em casa somente a díade participante e a pesquisadora, para evitar possíveis interrupções. As observações aconteceram em uma situação de brinquedo livre. De acordo com Borges e Salomão (2003), as situações de brinquedos livres permitem que as trocas interativas entre as díades ocorram de forma espontânea e natural, estando próximo daquilo que ocorre no dia a dia. Essa situação caracteriza-se por solicitar que a mãe brinque com a criança como normalmente o faz. Foram realizadas três observações para cada díade, com duração de 20 minutos cada uma.

A escolha pela realização de três filmagens por díade participante foi feita em virtude do objetivo de verificar os comportamentos comunicativos e a configuração dos episódios interativos entre a mãe e o bebê e, assim, atentar para as estratégias comunicativas utilizadas durante as três observações realizadas. Devido a questões pessoais dos participantes, como viagens e imprevistos no que concerne à saúde da criança, não foi possível demarcar um tempo exato entre as observações realizadas. No entanto, cabe destacar que não foi ultrapassado o intervalo de dois meses entre cada etapa.

Para a análise das observações foram utilizados 10 dos 20 minutos de filmagem, descartando-se os cinco minutos iniciais e os cinco finais. Considera-se que os 10 minutos intermediários fornecem informações suficientes sobre a interação entre a díade, a qual, por sua vez, nesse período, pode se mostrar mais confortável com a presença do observador e da câmera filmadora.
As observações realizadas tiveram subsídio analítico de dois dos três componentes do sistema computacional Child Language Data Exchange System (CHILDES), a saber: o Codes for Human Analysis Transcripts (CHAT), que consiste em um sistema de transcrição ou codificação dos dados, permitindo que o pesquisador obtenha níveis precisos; e o Computorized Language Analysis (CLAN), que permite ao pesquisador a obtenção de níveis crescentes de precisão tanto na transcrição quanto na codificação dos dados (Salomão, 1996).

Inicialmente foram feitas várias leituras dos fluxos interativos constituintes das díades em cada uma das três observações, a fim de verificar as características, as variações e a participação individual da mãe e do bebê. A participação da mãe foi analisada através de sua comunicação verbal e não verbal, isto é, os gestos, expressões e estratégias utilizadas de modo a envolver o bebê na interação. A participação dos bebês durante a interação foi basicamente do tipo não verbal. As categorias foram formuladas com base em uma observação mãe-bebê com deficiência visual, em alguns estudos da área (Aquino, 2008; Bosa, 2002; Braz \& Salomão, 2002; Salomão, 1996) e com base nos objetivos da pesquisa. É importante destacar que algumas categorias também foram formuladas com base na literatura de base, qual seja, a Perspectiva da Interação Social dos Estudiosos da Linguagem, a qual preconiza o uso, por exemplo, de diretivos e requisições em situações interativas. No entanto, outras categorias surgiram em virtude dos protocolos obtidos através das filmagens, como os comentários; o contato físico e as atividades de cuidado.

Portanto, os estilos de fala materna foram analisados considerando as seguintes categorias: Diretivos: quando a mãe tende a dirigir a atenção e/ou as ações do bebê. Podem ser apresentados como um comando ou ordem. Requisições: quando a mãe solicita respostas verbais ou não verbais por parte da criança a objetos, situação ou ação. Sua principal finalidade é promover a participação da criança na interação. Comentários: comentários que a mãe faz dirigidos ora ao bebê, ora de forma geral, apenas com o intuito de verbalizar. Feedbacks: quando a mãe aprova ou não ações e comportamentos do bebê. É também um pedido materno de clarificação dos enunciados da criança ou de suas ações. Pode ser verbal ou não verbal.

Os comportamentos não verbais maternos foram analisados através das seguintes categorias: 
Contato Físico: quando a mãe se aproxima da criança e a toca, seja no sentido de ajudá-la em alguma atividade, seja para chamar sua atenção, podendo ocorrer por meio do contato com as mãos da mãe ou através de objetos compartilhados. Gestos: formas gestuais utilizadas pela mãe para interagir com a criança e para complementar a fala. Podem ser gestos de oferecer objetos, entregar objetos, gestos não verbais de aprovação/ desaprovação, dentre outros. Observação: quando a mãe observa o bebê, seja quando ele está se dirigindo a alguma atividade, seja quando não há nenhum outro elemento e o bebê apenas se mostra presente. Demonstração de afeto: quando a mãe demonstra carinho para com o bebê, seja abraçando-o ou beijando-o e Atividades de cuidado: quando a mãe realiza atividades do tipo pegar o bebê no colo, acalentar e amamentar.

A participação dos bebês foi basicamente do tipo não verbal, dada a faixa etária em que se encontravam durante as filmagens. Foram elaboradas as seguintes categorias: Resposta à solicitação da mãe: quando o bebê responde a um pedido da mãe, de forma verbal e/ou não verbal. Demonstração de afeto: quando o bebê demonstra carinho ou desejo de receber carinho, mediante aproximação corporal com a mãe ou emissão de sorriso e risadas. Demonstração de desagrado: o bebê demonstra desaprovação, por meio do choro, por exemplo. Iniciativa do bebê: quando o bebê toma a iniciativa durante a interação, seja dirigida somente à mãe, seja dirigida a um objeto ou a ambos. Comportamento não verbal espontâneo: comportamento não verbal do bebê que não é precedido por uma ação ou enunciado da mãe. Pode ser relacionado à manipulação de objetos ou aos movimentos corporais espontâneos, como levantar e baixar membros, dentre outros. Vocalizações: quando não é possível compreender o que está sendo dito pelo bebê, assemelhando-se a balbucios, mas que apresenta uma função comunicativa. Emissão de gestos e/ou movimentos: quando o bebê apresenta gestos que são indicativos de alguma intenção. Podem ser gestos de tocar a mãe, estender os braços ou bater palmas durante uma canção.

No que diz respeito aos episódios interativos que indicam, ou não, cenas de atenção conjunta, a categorização ocorreu da seguinte forma: Episódios interativos contínuos indicativos de atenção conjunta: são episódios em que a mãe e o bebê estão voltados para a mesma atividade ou objeto e compartilham a atenção. Episódios interativos descontínuos que não indicam atenção conjunta: são episódios em que o bebê ou a mãe promovem a descontinuidade na interação, ao se voltarem para uma atividade ou um objeto individualmente.

\section{Resultados e Discussão}

Nesta seção serão apresentados e discutidos os resultados obtidos com as díades mãe-bebê com deficiência visual, de forma individual, através da descrição de cada observação realizada.

Díade 1: Essa díade caracteriza-se por um bebê que, no início da realização das filmagens, tinha onze meses de vida e, além da deficiência visual, apresentava problemas respiratórios e atraso cognitivo. Na primeira filmagem, caracterizada por uma situação de atividade de cuidado, através da alimentação do bebê, a mãe fez uso maior dos diretivos, sobretudo os diretivos de atenção, além da solicitação de respostas ao bebê. Sempre que o bebê respondia à solicitação da mãe, recebendo o alimento, por exemplo, ela lhe atribuiu feedbacks do tipo positivo. Além do contato físico estabelecido com o bebê, através do fornecimento do alimento, a mãe também esteve durante boa parte da interação tocando-o, com o objetivo de manter a proximidade com ele. 0 bebê, por sua vez, apresentou comportamentos do tipo não verbal espontâneo, ou seja, movimentou os membros do corpo e virou a cabeça em posição contrária à mãe. Considerando que a situação se caracterizou por interativa contínua e que tanto a mãe quanto o bebê estavam voltados para um mesmo evento, pode-se inferir que foi configurada uma cena de atenção conjunta, a qual aconteceu, sobretudo através do toque entre a mãe e o bebê. A segunda observação aconteceu em uma situação diferente, em que o bebê e a mãe estiveram deitados em uma cama. Brinquedo musical, ursinhos de pelúcia e objetos de plástico constituíram a cena interativa. Os estilos linguísticos mais utilizados pela mãe foram, assim como na primeira filmagem, os diretivos e as solicitações.

A mãe novamente fez contato físico com o bebê e também demonstrou carinho para com ele, através de beijos e de abraços. No entanto, o bebê apresentou comportamentos de desagrado, ameaçando chorar, e 
muitas vezes demonstrou desinteresse nas atividades que a mãe propunha, caracterizando episódios interativos descontínuos, que não indicaram atenção conjunta. A última filmagem aconteceu em uma situação de cuidado, em que a mãe realizou uma troca de roupa no bebê, que novamente demonstrou desagrado com a situação, além do comportamento não verbal espontâneo, conforme visto na primeira filmagem. Para tanto, a mãe fez uso dos diretivos, especialmente os diretivos de atenção e de instrução, e, diferentemente das filmagens anteriores, observou bastante o bebê e seu comportamento. Os episódios interativos contínuos aconteceram devido à própria situação da interação, na qual o bebê e a mãe estiveram focados na atividade de troca.

Díade 2: No início das observações, o bebê estava com doze meses de vida. Na primeira e segunda filmagens, os diretivos e as requisições foram o estilo de fala mais utilizado pela mãe, enquanto na terceira filmagem sobressaíram-se os feedbacks. As situações interativas, nos três momentos, envolveram basicamente a mesma cena, isto é, sentados em uma cama, a mãe utilizou alguns brinquedos, como bonecas e ursinhos, além de movimentar o corpo do bebê, muitas vezes, apenas observando-o, em silêncio. O bebê apresentou comportamentos espontâneos, movimentando os braços e pernas, mas também teve a iniciativa, na terceira filmagem, de bater palmas, o que levou a mãe a cantar parabéns prá você, indicando um episódio contínuo, com destaque para a atenção conjunta. A brincadeira iniciada pela mãe de segurar o bebê pelas costas para que ele não caísse e o uso da fala "mamãe vai soltar, seguraaaa", seguida da resposta do bebê de cair deitada no colchão e novamente se sentar para novamente cair, pode constituir um episódio interativo contínuo. Em outro momento, verifica-se a continuidade através da repetição vocal, ou seja, o bebê fala "hummm" e a mãe repete, levando-o bebê a emitir novamente o mesmo som. Segundo Nogueira (2009), a base da comunicação pré-verbal infantil está relacionada tanto aos gestos de apontar, mostrar e alcançar, como aos comportamentos iniciais de vocalizar, emitir diferentes expressões faciais e movimentar o corpo de forma variada. Logo, por se tratar de um bebê com deficiência visual, não foi possível observar o comportamento de apontar para um objeto, por exemplo, mas sua vocalização indicou os primeiros sinais de uma comunicação verbal.
Díade 3: Esse bebê, no início das observações, estava com apenas seis meses de vida. Diferentemente das outras díades, a mãe, durante a maior parte das observações, apenas observou o bebê e cantou canções para ele, não fazendo uso de objetos externos que pudessem compor a cena interativa. Na primeira filmagem o bebê estava no colo da mãe, que utilizou do contato físico e dos gestos, levando o bebê a apresentar comportamentos espontâneos. Quando o bebê tentou aproximar a própria roupa da boca, comportamento característico de sua faixa etária, a mãe o interrompeu, caracterizando uma descontinuidade na interação. Na segunda e terceira observações a mãe fez uso dos diretivos, das requisições e novamente do ato de cantar. Na segunda filmagem a descontinuidade pode ser verificada quando a mãe solicita que o bebê faça besourinhos com a boca e ele vira a cabeça e começa a chorar. A mãe, então, levanta o bebê e o senta a seu lado. A interação contínua acontece em outro momento da observação, no qual a mãe levanta o bebê no ar e ele sorri, indicando interesse na atividade realizada. $O$ bebê, inclusive, sinaliza sua excitação através da vocalização, que parece indicar euforia. De acordo com Mendes (2009), as manifestações de afeto por parte das mães parecem influenciar o comportamento dos bebês. Nesta observação, foi o comportamento do bebê de demonstrar satisfação que influenciou o comportamento da mãe em continuar a atividade por ela iniciada. Na última observação, o bebê esteve deitado no sofá, com mãe sentada a seu lado. Um episódio interativo contínuo que indica atenção conjunta aconteceu quando a mãe colocou um ursinho em cima do bebê e ele o segurou. O reforço na interação aconteceu quando o bebê vocalizou "êêê" e a mãe repetiu, solicitando que ele conversasse com ela. $\mathrm{O}$ bebê então vocalizou "hummm" e a mãe novamente repetiu, movimentando para a frente e para trás as pernas do bebê, que demonstrou entusiasmo.

De modo geral, no que diz respeito aos estilos comunicativos maternos, foi possível verificar que nas mães de bebês com deficiência visual, os diretivos, sobretudo os diretivos de atenção foram os enunciados maternos mais utilizados, atuando com a função de direcionar a atenção do bebê e melhor envolvê-lo nas atividades propostas. Segundo Aquino e Salomão (2009), o uso desses diretivos por parte dos genitores acontece por- 
que a criança ainda apresenta uma habilidade linguística e cognitiva limitada, e somente através do desenvolvimento delas é que será possível a diferenciação e identificação das variadas formas diretivas, isto é, desde os simples comandos até a sutileza dos atos de fala que exigem maiores conhecimentos.

O uso das requisições, através da solicitação de resposta, juntamente com o uso dos feedbacks de aprovação/desaprovação, foi também bastante utilizado, sendo, em muito dos casos, consequência do comportamento infantil. De forma semelhante aos resultados encontrados por Braz (2000), o uso das solicitações de respostas atuou como uma forma encontrada pelas mães para dar continuidade às ações realizadas pela díade, bem como para dar suporte na interação com o bebê, mantendo-o engajado. No que tange ao uso dos feedbacks, eles foram utilizados em número reduzido, mas apareceram principalmente em situações em que os bebês tentavam iniciar uma nova atividade e a mãe fornecia uma resposta verbal de aprovação ou não.

Provavelmente devido à faixa etária dos bebês e a seu nível linguístico, as atividades propostas e realizadas pelas díades colaboraram para que as mães, durante boa parte do tempo da filmagem, apenas observassem os bebês e suas ações, deixando-os mais livres. Os bebês, por sua vez, apresentaram comportamentos caracterizados como não verbais espontâneos, principalmente através do movimento corporal. Esses comportamentos espontâneos são relevantes para as investigações, haja vista que resultam no comportamento mais diretivo da mãe, uma vez que o bebê tende a ter menos iniciativa durante a interação. Os bebês também apresentaram respostas às solicitações maternas, ora adequadas ora inadequadas, como, por exemplo, bater palmas quando a mãe sugeria cantar parabéns ou iniciar uma atividade que não envolvia sua participação direta. Logo, através da resposta dada pelos bebês, as mães introduziam novas atividades e novos objetos, sempre com a intenção de manter a interação e, assim, manter o bebê envolvido na situação por ela proposta.

De acordo com Seidl de Moura (2009), ao se envolverem com os bebês, os adultos os estimulam através do contato corporal, observam as suas reações e ajustam o seu comportamento de acordo com o que percebem. Sendo assim, as pistas dadas pelos bebês às mães irão possibilitar a continuidade nas interações e favorecerão a explicação da capacidade de atenção conjunta (Tomasello, 2003).

Em suma, a análise realizada possibilitou verificar os aspectos em comum das díades, mas também as diferenças individuais, provavelmente decorrentes das diferenças de idade dos bebês, além de outros comprometimentos ocasionados pela prematuridade, conforme verificado nos episódios interativos da primeira díade.

\section{Considerações Finais}

Os estudos desenvolvidos sobre interação social e desenvolvimento linguístico, evidenciam que há padrões de estilos comunicativos que são característicos, ou seja, a idade da criança, a sua capacidade cognitiva e o seu desenvolvimento linguístico influenciam os inputs maternos utilizados. As pesquisas mostram, ainda, que há diferença no estilo de fala da mãe em relação à criança com desenvolvimento típico e à criança com desenvolvimento atípico. Especificamente, os estudos realizados com crianças cegas, evidenciam que estas têm mais dificuldades em explorar o ambiente e se posicionarem, e que o desenvolvimento de episódios de atenção conjunta sofre influências do contexto social em que os membros da díade estão engajados. A linguagem será um recurso a mais no estabelecimento destes contextos interativos e no ato de direcionar a atenção da díade para um terceiro objeto ou evento.

O objetivo deste estudo foi analisar a interação mãe-bebê com deficiência visual, através da identificação dos comportamentos comunicativos maternos e dos comportamentos comunicativos infantis, além da identificação de episódios interativos. Nesse sentido, as mães de bebês com deficiência visual comunicam-se através dos diferentes estilos linguísticos, com predomínio dos diretivos. Considera-se que o alto número de diretivos está relacionado, entre outras características da díade, à idade e ao nível linguístico da criança. 0 contato físico, através do toque corporal, é também uma forma de comunicar ao bebê a sua presença. De fato, muitas vezes o termo diretivo "olha, olha aqui" foi utilizado com o gesto de pegar a mão do bebê e aproximar a um objeto.

A partir da identificação dos estilos de fala materna utilizados durante o contexto interacional, dos 
comportamentos não verbais maternos, dos comportamentos comunicativos infantis e da identificação de episódios interativos contínuos e/ou descontínuos, pensa-se ser possível compreender as estratégias maternas que visam facilitar e/ou dificultar a participação do bebê durante o processo interacional. Desse modo, os dados possibilitam pensar questões sobre o desenvolvimento infantil, especificamente o desenvolvimento linguístico de bebês deficientes visuais.

Ademais, apesar da limitação do estudo aqui apresentado, uma vez que o número de participantes foi pequeno, o que se justifica devido aos critérios de inclusão previamente estabelecidos e à dificuldade de encontrar bebês com deficiência visual total, pode-se afirmar que os resultados obtidos possibilitaram uma melhor compreensão da configuração dos episódios interativos estabelecidos entre as díades, com destaque para os contextos de atenção conjunta.

Nesse sentido, são fundamentais estudos longitudinais que visem a coleta de informações acerca do desenvolvimento inicial das crianças deficientes visuais, haja vista que poderão facilitar as expectativas parentais no que diz respeito ao desenvolvimento e à capacidade dos filhos. É relevante que se empreendam estudos que se proponham a investigar a interação mãe-bebê com deficiência visual e enfoquem não apenas os estilos comunicativos maternos e as respostas dos bebês, mas que também obtenham dados referentes à formação do vocabulário, pois possibilitam estruturar intervenções já nos primeiros anos de vida do bebê com deficiência visual.

\section{Referências}

Akhtar, N., Dunham, F., \& Dunham, P. (1991). Directive interactions and early vocabulary development: the role of joint attentional focus. Journal of Child Language, 18 (1), 41-49.

Akthar, N., \& Gernsbacher, M. (2007) Joint attention and vocabulary development: a critical look. Language and Linguistic Compass, 1 (3), 195-207.

Aquino, F. (2008). Intencionalidade comunicativa e atenção conjunta: uma análise em contextos interativos mãe-bebê. Tese de doutorado não-publicada, Universidade Federal da Paraíba, João Pessoa.

Aquino, F., \& Salomão, N. M. R. (2009). Contribuições da habilidade da atenção conjunta para a cognição social infantil. Psicologia em Estudo, 14 (2), 233-241.
Bates, E., Dale, P., \& Thal, D. (1997). Diferenças individuais e suas implicações para as teorias do desenvolvimento da linguagem. In P. Fletcher \& B. MacWhinney (Orgs.), Compêndio da linguagem da criança (pp.87-130). Porto Alegre: Artes Médicas.

Batista, C. (1997). Desenvolvimento da criança com deficiência visual: enfoques e resultados de pesquisas. Anais da XXVII Reunião Anual de Psicologia, Ribeirão Preto.

Bigelow, A. (2003) The development of joint attention in blind infants. Development and Psychopathology, 15 (2), 259-275.

Borges, L., \& Salomão, N. M. R. (2003). Aquisição da linguagem: considerações da perspectiva da interação social. Psicologia: Reflexão e Crítica, 16 (2), 327-336.

Bosa, C. (2002). Atenção compartilhada e identificação precoce do autismo. Psicologia: Reflexão e Crítica, 15 (1), 77-88.

Bosa, C., \& Souza, A. (2007). Interação mãe-criança e desenvolvimento atípico: a contribuição da observação sistemática. In C. Piccinini \& M. Seidl de Moura (Orgs.), Observando a interação pais-bebê-criança: diferentes abordagens teóricas e metodológicas (pp.213-236). São Paulo: Casa do Psicólogo.

Braz, F. (2000). A fala dirigida a meninos e meninas: um estudo sobre o input materno e suas variações. Dissertação de mestrado não-publicada, Universidade Federal da Paraíba, João Pessoa.

Braz, F., \& Salomão, N. M. R. (2002). Episódios de atenção conjunta em um contexto de brincadeira livre. Interações, 7 (14), 85-104.

Conti-Ramsden, G. (1990). Maternal recasts and other contingent replies to language-impaired children. Journal of Speech and Hearing Disorders, 55 (2), 262-274.

Conti-Ramsden, G. (1994). Language interaction with atypical language learners. In C. Gallaway \& B. Richards (Orgs.), Input and interaction in language acquisition (pp.183-198). London: Cambridge University Press.

Fônseca, P., \& Salomão, N. M. R. (2005). Análise comparativa das falas materna e paterna dirigidas às crianças. Paidéia, 15 (30), 79-91.

Fraiberg, S. (1979). Blind infants and their mothers: an examination of the sign system. In M. Bullowa. Before speech: the beginning of interpersonal communication (pp.149-170). London: Cambridge University Press.

Hampson, J., \& Nelson, K. (1993). The relation of maternal language to variation in rate and style of language acquisition. Journal of Child Language, 20, 313-342.

Kreutz, C., \& Bosa, C. (2009). Intervenção precoce na comunicação pais-bebê com deficiência visual. Estudos de Psicologia (Campinas), 26 (4), 537-544. doi: 101590/S0103-16 6X2009000400013.

Mendes, D. (2009). As expressões emocionais e o desenvolvimento inicial. In M. Seidl de Moura, D. Mendes \& L. Pessôa (Orgs.), Interação social e desenvolvimento (pp.71-85). Curitiba: CRV.

Nelson, K. E., Welsch, J., Camarata, S. M., Butkovsky, L., \& Camarata, M. (1995). Available input for language impaired children and younger children of matched language levels. First Language, 15 (1), 1-17. 
Nogueira, S. (2009). A comunicação pré-verbal. In M. Seidl de Moura, D. Mendes \& L. Pessôa (Orgs.), Interação sociale desenvolvimento (pp.101-115). Curitiba: CRV.

Oliveira, J., \& Marques, S. (2005). Análise da comunicação verbal e não verbal de crianças com deficiência visual durante a interação com a mãe. Revista Brasileira de Educação Especial, 11 (3), 409-428.

Oliveira, T., \& Gil, M. (2007). Elementos fundamentais para a aquisição de operantes verbais por bebês: análise comportamental da "atenção compartilhada". Revista Brasileira de Terapia Comportamental Cognitiva, 9 (2), 217-225.

Pérez-Pereira, M. (2004). Desenvolvimento da linguagem. In C. Coll, J. Palácios \& A. Marchesi (Orgs.), Desenvolvimento psicológico e educação (Vol.1, 2a ed., pp.160-180). Porto Alegre: Artmed.

Pérez-Pereira, M., \& Conti-Ramsden, G. (2001). The use of directives in verbal interactions between blind children and their mothers. Journal of Visual Impairment\&Blindness, 95 (3), 133-149.

Pine, J. M. (1994). The language of primary caregivers. In C. Gallaway \& B. Richards (Orgs.), Input and interaction in language acquisition (pp.15-37). London: Cambridge University Press.

Rochat, P. (2007). Intentional action arises from early reciprocal changes. Acta Psychologica, 124 (1), 8-25.

Salomão, N. M. R. (1996). Interaction between mothers and children with specific language impairment: a longitudinal study. Unipublish doctoral dissertation, University of Manchester, United Kingdon.

Seidl de Moura, M. (2009). Interações sociais e desenvolvimento. In M. Seidl de Moura, D. Mendes \& L. Pessôa (Orgs.), Interação social e desenvolvimento (pp.19-36). Curitiba: Editora CRV.

Seidl de Moura, M., Ribas, A., Seabra, K., Pessoa, L., Nogueira, S., Mendez, D., et al. (2008). Interações mãe-bebê de um e cinco meses de díades urbanas: aspectos afetivos, comportamentos, complexidade e sistemas parentais predominantes. Psicologia: Reflexão e Crítica, 21 (1), 66-73.

Snow, C. (1997). Questões no estudo do input: sintonia, universalidade, diferenças individuais e evolutivas, e causas necessárias. In P. Fletcher \& B. MacWhinney (Orgs.), Compêndio da linguagem da criança (pp.153-163). Porto Alegre: Artes Médicas.

Tomasello, M. (2003). Origens culturais da aquisição do conhecimento humano. São Paulo: Martins Fontes.

Vila, I. (1995). Aquisição da linguagem. In C. Coll, J. Palácios \& A. Marchesi (Orgs.), Desenvolvimento psicológico e educação (Vol.1, pp.69-80). Porto Alegre: Artes Médicas.

Recebido em: 20/6/2012

Aprovado em: 20/7/2012 